\title{
Suicide Stigma in Christian Faith Communities: A Qualitative Study
}

\author{
Karen Mason (iD)
}

check for

updates

Citation: Mason, Karen. 2021. Suicide Stigma in Christian Faith Communities: A Qualitative Study. Religions 12: 540. https://doi.org/ $10.3390 /$ rel12070540

Academic Editor: Curtis Lehmann

Received: 1 June 2021

Accepted: 14 July 2021

Published: 16 July 2021

Publisher's Note: MDPI stays neutral with regard to jurisdictional claims in published maps and institutional affiliations.

Copyright: (C) 2021 by the author. Licensee MDPI, Basel, Switzerland. This article is an open access article distributed under the terms and conditions of the Creative Commons Attribution (CC BY) license (https:/ / creativecommons.org/licenses/by/ $4.0 /)$.
Counseling Department, Gordon-Conwell Theological Seminary, South Hamilton, MA 01982, USA;

kmason@gordonconwell.edu

\begin{abstract}
Given the increasing numbers of U.S. lives lost to suicide, it is imperative to identify factors that can help protect against suicide. While regular religious service attendance has been found to be protective against suicide, faith communities have taboos against suicide which may be associated with stigma. Nine Christian faith leaders and congregants and one moral psychologist completed interviews on suicide stigma in Christian faith communities. Themes that emerged included internal, interpersonal, and theological components and group differences related to suicide stigma in Christian faith communities. Participants proposed seven barriers and seven corresponding ways to address suicide stigma in Christian faith communities: talk about suicide, address skill deficits, practice vulnerability, get leadership on board, address the theology of suicide, appreciate that faith communities have a unique contribution to make to suicide prevention, and address cultural/systemic issues.
\end{abstract}

Keywords: suicide; stigma; faith communities

\section{Introduction}

Suicide is a growing tragedy in the U.S. The number of Americans lost to suicide has steadily climbed from 29,199 in 1999 to 48,344 in 2018 (CDC 2005), more than the number of those lost to opioid overdose in 2018: 46,802 (Hedegaard et al. 2020). Given the increasing numbers of lives lost to suicide, it is imperative to identify factors that can help protect against suicide. Regular religious service attendance has been found to be protective against suicide in large prospective cohort studies (Chida et al. 2009; Li et al. 2016a, 2016b; VanderWeele et al. 2016). VanderWeele (2018) notes, "Something about the communal religious experience seems to matter. Something powerful takes place there" (p. 108). Many have suggested that what is important about faith communities is social support (VanderWeele et al. 2017). While social isolation is a public health crisis (Holt-Lunstad 2017), social support cannot explain all the benefits of faith communities. Social support in religious service attendance explains only about a quarter of the association between attendance and health (VanderWeele et al. 2017). People join faith communities to "live a life of faith together" (Mason et al. 2019b, p. 614).

A possible protection is the breadth of engagement that faith leaders have with suicide in their faith communities (National Action Alliance for Suicide Prevention: Faith Communities Task Force 2019) from prevention (e.g., fostering a caring community), to intervention (e.g., helping a suicidal person), to postvention (e.g., caring for survivors) (Mason et al. 2019a).

Another possible protection is moral objections to suicide (MOS) which shape a person's beliefs and behaviors (Lawrence et al. 2016). Models of moral cognition are not well understood (Koleva et al. 2012; Rottman et al. 2014). Koleva et al. (2012) acknowledge that while evolutionary processes and personality differences may be factors in moral cognition, moral intuitions are a "largely unexplored psychological mechanism" (p. 184).

While underexplored, cognitions related to moral judgments can include expectations that others will adhere to local cultural norms such as not licking someone's shoe or picking 
up a used Band-Aid; these local cultural norms have been found to shape moral judgments and purity judgments in particular (Chakroff and Young 2015).

These culturally-based standards may be related to the concept of taboos, which are conventions or norms that inhibit a behavior (Tannenwald 2007) and can be religiouslyinformed prohibitions regarding the breaking of a sacred value (Tetlock 2003). Religious communities have taboos (Saroglou 2011). MOS may represent a subset of taboos, though non-religious people also have MOS. For example, Rottman et al. (2014) write, "People with stronger beliefs that their life belongs to God and that life is sacred are more disapproving of suicide" (p. 218). They add, "Even self-described non-religious liberals consider suicide to be morally wrong" (p. 223).

These taboos or prohibitions have been found to be based on cognitive processes such as one or more of the five moral foundations: care-harm, fairness-cheating, in-group loyalty-betrayal, respect for authority-subversion, and purity-degradation (McKay and Whitehouse 2015, p. 453). Koleva et al. (2012) write,

Morality is a complex and culturally variable construction. Different societies build different moralities, and they do so in part by resting their moral virtues, claims, and institutions to varying degrees on each [of five] moral foundation[s]. Furthermore, subcultures within the same society may also elaborate and emphasize different foundations to different degrees (p. 185).

These five foundations are described as "five innate psychological systems" (Koleva et al. 2012, p. 185) because each of the moral domains of the Moral Foundations Theory (MFT) has distinct cognitive signatures (Graham et al. 2011).

The purity/sanctity domain has been found to be a dominant domain in political issues (Koleva et al. 2012), where impurity results from breaking a sacred value (Chakroff and Young 2015). A "purity/sanctity" foundation of morality encompasses transgressions that are considered wrong because they contaminate or degrade a sacred entity (Koleva et al. 2012). Rottman et al. (2014) found that individual differences in the moral condemnation of suicide stem from variance in the tendency to value purity/sanctity, and, in particular, variance in concerns regarding the defilement of the soul. "Suicide is considered wrong to the extent that it taints the soul—not the degree to which it is perceived as harmful" (p. 223). They conclude, "Suicide should be classified as a purity-based violation" (p. 223).

Another process in moral cognition is evaluating the statistical infrequency or atypicality of an act (Chakroff and Young 2015). An abnormal or atypical act is likely to be viewed as an impure act that violates the purity of the person.

These cognitions seem to be automatic. Koleva et al. (2012) recognize that each of these five psychological systems produces "fast, automatic gut-reactions of like and dislike when certain patterns are perceived in the social world, which in turn guide judgments of right and wrong" (p. 185). Rottman et al. (2014) specify, "Moral judgments of suicide are not only complex but connected to potentially unexpected, implicit conceptual concerns" (p. 224) that are "intuitive" (p. 223).

The relationship between taboos and stigma is not known. Goffman (1963) defines stigma as an "attribute that is deeply discrediting" (p. 3). Rottman and Young (2019) suggest that the discredited attribute or "impure taint" is related to stigma. A purity judgement regarding a taint generates a sense of moral disgust (Tybur et al. 2013). Disgust is a feeling of strong distaste or repulsion which are automatic "flashes of approval or disapproval ... that pop into consciousness without our being aware of the mental processes that led to them" (Haidt and Joseph 2004, p. 56). The feeling of disgust is associated with a feeling that something pure has been degraded (Rottman et al. 2014). Suicide degrades the soul and makes it impure (Rottman et al. 2014). Rottman and Young (2019) propose the mere-trace hypothesis, that any amount of a transgression taints the person. They write, "Even slight contamination will render a person 'tainted.' This stigma will tend to surround them nearly as much as if they had engaged in an action many times over or many times more severely" (p. 1158). 
Impure, tainted people tend to be cast out of groups and marginalized through stigma (Binnix et al. 2017). Group members who violate taboos are avoided (McKay and Whitehouse 2015). Rottman and Young (2019) found that purity violations (like suicide) taint a person more than harm violations, which are anything that cause others to suffer, such as punching someone in the nose. They conclude that harm violations carry less stigma and are easier to change.

Suicide stigma is found in religious organizations (Allen-Ervin 2017) but the relationship between religious affiliation and suicide stigma seems complex based on a finding in a Turkish sample that those undergoing secular education were less accepting of a suicidal close friend than those undergoing religious education (Eskin 2004). As noted by Binnix et al. (2017), "Stigma are cultural in so far as groups can develop stocks of knowledge and tacit assumptions about stigma" (pp. 3-4) so stigma in Christian faith communities may be related to cultural norms but also to particular assumptions about suicide unique to Christian faith communities. Lawrence et al. (2016) have suggested that religion might reduce suicide risk through shaping a person's beliefs through MOS.

Suicide stigma is an important variable to study because it may be related to an increase in suicide risk. In a large cross-sectional study of 153,635 college students from 2007 to 2018, perceived public stigma of receiving mental health treatment and suicidality was significantly associated with greater odds of suicide ideation, planning, and attempt (Goodwill and Zhu 2020).

The question then arises: how does suicide stigma operate in faith communities? This seems to be an understudied area. While the associations between Christian beliefs, suicide stigma, and suicide risk are not known, religiously-informed moral cognitions may be related to an unknown mix of evolutionary and personality factors, local cultural norms, taboos, MOS, moral foundations like purity or harm, and the statistical atypicality of events, all potentially contributing to suicide stigma and suicide risk. This qualitative study will explore the types of suicide stigma found in U.S. Christian faith communities, how stigma may decrease or increase suicide risk and how faith leaders and congregants address suicide stigma.

\section{Materials and Methods}

\section{Participants}

Qualitative methodology is exploratory and is "especially useful when the researcher does not know the important variables to examine" (Creswell 2014, p. 20), such as how stigma operates in U.S. Christian faith communities. Thematic analysis is a recognized qualitative methodology (Braun and Clarke 2006, 2012, 2013). The focus of the study is on gaining "appreciative understanding" (Gergen et al. 2015, p. 3) of how U.S. Christian faith leaders and congregants understand suicide stigma and how it operates in faith communities. Gordon-Conwell Theological Seminary's Institutional Review Board approved the study on 25 January 2021.

A convenience sample of nine U.S. Christian participants was selected based on their public engagement with suicide prevention in nine different U.S. Christian faith communities, though all have broader involvement with U.S. faith communities. It was anticipated that informants willing and able to articulate their thoughts about suicide stigma in faith communities would be those who were publicly involved in suicide prevention. Table 1 presents the demographics of participants, though the salient characteristic of participants is their public engagement with suicide prevention in U.S. faith communities. The Christian faith includes Catholics and Protestants. One moral psychologist based in the U.S. was selected to provide perspective on stigma and religion. Each participant provided consent before beginning the interview. 
Table 1. Participant demographics.

\begin{tabular}{|c|c|}
\hline Demographic Characteristics & Study Participants \\
\hline Gender & $\begin{array}{c}7 \text { males } \\
3 \text { females }\end{array}$ \\
\hline Age & $\begin{array}{l}170 \mathrm{~s} \\
460 \mathrm{~s} \\
350 \mathrm{~s} \\
140 \mathrm{~s} \\
130 \mathrm{~s}\end{array}$ \\
\hline Denomination & $\begin{array}{c}3 \text { Baptist (American Baptist, Baptist, and Full Gospel Baptist) } \\
2 \text { United Church of Christ } \\
1 \text { Evangelical Lutheran Church of America } \\
1 \text { United Methodist Church } \\
1 \text { Reformed Church of America } \\
1 \text { Roman Catholic } \\
1 \text { unaffiliated }\end{array}$ \\
\hline Role & $\begin{array}{c}4 \text { congregants } \\
5 \text { faith leaders } \\
1 \text { moral psychologist }\end{array}$ \\
\hline Race & $\begin{array}{l}1 \text { black } \\
9 \text { white }\end{array}$ \\
\hline U.S. Census Bureau Region & $\begin{array}{l}1 \text { Northeast } \\
4 \text { South } \\
3 \text { Midwest } \\
1 \text { West }\end{array}$ \\
\hline Experience with suicide & $\begin{array}{c}5 \text { survivors of family member suicide } \\
1 \text { survivor of suicide in community } \\
1 \text { survivor of suicide in a professional role } \\
1 \text { participant with lived experience of suicide } \\
2 \text { unknown }\end{array}$ \\
\hline
\end{tabular}

One-hour semi-structured interviews were audio-recorded and transcribed using a sample of questions found in Appendix A. Themes began to replicate after the first five interviews and reached saturation by the tenth interview. Results are considered trustworthy because all but two participants provided edits to their transcript and they expressed resonance with the final themes. An independent qualitative researcher consulted with the researcher to review the conduct of the study.

Transcripts were analyzed using thematic analysis (Braun and Clarke 2006, 2012, 2013). The researcher used a complete coding approach to generate data-derived (or semantic) codes, segments of meaning in the data (i.e., the transcripts). The researcher assigned them names, moving back and forth from the data to the codes to collate all instances in the transcripts where the codes appear, to capture the diversity of the meanings expressed by participants. These codes were then analyzed for patterns which were identified as candidate themes. Candidate themes were compared with the data to confirm them or revise them to ensure faithfulness to the data. Final themes were defined and illustrated by quotations that tell the story of suicide stigma in faith communities as articulated by the participants and as analyzed by the researcher.

Protestant participants, faith leaders, and congregants are numbered P1-P8. C1 designates a Catholic congregant and M1 a moral psychologist. When participants referred to people "touched by suicide," they included suicidal people, people who have attempted, or people who have lost a loved one to suicide. 


\section{Results}

\subsection{Definition}

Participants defined stigma as "a mark, a stain, a wound, a scar" (P2) resulting in "a negative self-image" (P3), "internal shame" (P1) or "deep shame" (P5), or "a moral blemish" (M1) which is "projected onto others" (P1). Others see someone touched by suicide as "different" (P6, P8). This difference results in others feeling "deep fear and great visceral discomfort" (C1), "recoil" (P3), or "disgust" (M1) because they see suicide as "tainting" a person (M1). This taint is "really hard to get rid of ... always there and hard to wash away" (M1). This mark is "for life" (P6). The definition of stigma comprised internal, interpersonal, and theological components.

\subsubsection{Internal}

Participants elaborated on the internal component of stigma. People touched by suicide see themselves "as somehow deficient" (P1). P3 clarified the view that "suicide is sick, selfish, or sinful." M1 explained that "[suicide] stigma is correlated with ... degradation or impurity" which is "sticky and hard to change and eradicate." P5 elaborated that shame also fuels silence: "If we don't talk about this, then it doesn't exist."

\subsubsection{Interpersonal}

Participants elaborated on the interpersonal component of stigma, specifically the projection that "others are looking at me differently" (P1). This projection occurs because others do not address suicide because of their discomfort, "the discomfort of people who don't know what to say, who don't say anything or they say pleasantries and it's obvious they're uncomfortable" (P1).

However, many participants were clear that shame is not entirely projection. People touched by suicide experience being "shunned" (P7). P5 said, "We tend to stay away from people who are not right." Shunning derives from fear. P7 clearly articulated this fear,

Our absolute fear that if [suicide] can happen to your family then it could happen to my family. Therefore, I will do everything possible to figure out how you are different from me.... We've got to figure out what you did wrong because then we can protect ourselves from this calamity happening. ... If I can push you away, if I can say this happened to you and your family, ... . then I can say, 'Whew, that ain't going to happen to me'.

$\mathrm{C} 1$ concurred, "There is something very wrong or broken with a suicidal person or a person who died by suicide. It's harmful; it's catching." M1 clarified that shunning derives from disgust,

"Disgust shrinks our moral circles. We tend to feel disgusted for all sorts of irrational reasons, particularly at out-group members who are unlike us, people who are stigmatized or marginalized in different ways. By feeling disgust, we seem to dehumanize people and not afford them the kind of moral concern that they deserve. There is less moral responsibility that we feel toward protecting their rights. ... we're going to distance ourselves not only from people who attempt or commit suicide but we're going to distance ourselves from the concept, from talking about suicide, by having this purity framework."

Shunning results in not helping a suffering congregant. It is as if the faith community is saying, "Your human suffering makes you ineligible to be a cared-for human being. It is too much to ask for the rest of us to help you, therefore you are a burden" (C1).

\subsubsection{Theological}

Participants elaborated on the theological components of stigma because "stigmas form around belief systems" (P3) and "a lot of the stigma around suicide ties into faith questions" (P4). The theological components mentioned by participants that influence stigma include old theology such as "suicide is the unforgivable $\sin ^{\text {" }}(\mathrm{C} 1)$ or that a person 
who dies by suicide cannot be buried in a cemetery (P4). P4 added, "Those traditions are so embedded in the culture that people don't even know where to look to find out if that's still true." She said that "people fill in that blank with old and often negative beliefs, such as suicide is a $\sin$," because suicide is not considered "an appropriate conversation to have in the church" (P5), because "people don't think about [suicide] from a biblical standpoint" (P3), because "people are unaware of the policy stances of their faith community (C1), and because changes in faith community policies "take a while to [filter down to] the average person" (P7). As noted by P5, these beliefs do not change easily, "Now all of a sudden [suicide] is happening. And it shakes the whole thing up and that frightens people.... People want to maintain their little belief box, and stay in it, and not come out."

\subsubsection{Differences}

A subtheme of the components of stigma is that stigma is likely to differ by culture, gender, urban/rural settings, and personality. Several participants mentioned the culture of not seeking help. P1 said, "Unless we talk about help-seeking regularly and about suicide more than occasionally, we develop or reinforce a culture of not seeking help." P2 explained not seeking help in the African American context because mental strength is required to withstand societal pressures. He cited research that " $63 \%$ of African Americans see mental health issues as a sign of weakness." He added another example of a cultural perspective, "In the African American tradition, a slave jumping off of a ship is an act of defiance ... there is a heroic element to suicide." Other differences that influence stigma which were mentioned included gender (P2), urban/rural contexts (P5), personality differences (M1, P7) and group membership (P8). For example, P8 said,

"It depends on the group and what is considered to be a stigma for them. You boil it down to rejection. The person is rejected. It's a non-connection. ... therefore you're isolated, on your own, you're rejected, so I will deal with this myself."

\subsection{Barriers}

Participants mentioned seven barriers to addressing suicide stigma in faith communities: silence, ignorance, expectations of "having it all together" (P5), expectations about the "preaching moment" (P2), being busy, an artificial division between mental health/suicide and faith, and the lack of training for faith leaders.

\subsubsection{Silence}

Many participants said faith communities are not addressing suicide. For example, P1 said there is "a tremendous amount of secrecy [around suicide]." P3 said, "People are sitting in church anonymously and they can't talk about it." P4 said, "There has not been good conversation around [suicide]." She attributes this to fear: "There is too much fear about talking about suicide."

\subsubsection{Ignorance}

P8 emphasized ignorance about suicide and death in general.

"It's ignorance. People are ignorant about death, about their own impending death, about how to be mature enough to reach out to people who need help, whether it is suicide or a family who has experienced suicide or [death] in general."

C1 said, "[Suicide] stigma is fear plus ignorance." Types of ignorance mentioned by participants included that suicide can only be addressed by professionals (P3, P4), that suicidal desperation doesn't exist in faith communities (P3) or that "you can plant the seed of the idea of suicide" by talking about it (P4). 
3.2.3. Expectation of not Struggling with Suicidal Behaviors and "Having It all Together" (P5)

The barrier mentioned most (by seven participants) is that people expect that faith will protect them from suffering including suicidal behaviors. P1 said, "Suffering is stigmatized in certain circles." Suffering is viewed as "the failure of faith" (P2). If suffering occurs, faith is expected to heal it. P2 explained that there is an expectation that "there is a word to heal everything ... not having that word is a weakness of the pastor and the person who died." Suicidal thinking is suffering that is unexpected in faith communities. P4 explained, "If you pray enough and go to church enough and are active enough in your faith life, then you're not going to experience suicidal thinking." A suicidal person "must not have had a strong enough faith" (P4). C1 elaborated,

"Suicide shows a chink in the faith armour. People touched by suicide, there is a something wrong with them, their faith practice, the strength of their faith ... People touched by suicide are not part of the elect. They are sinners who are irredeemable."

P6 added,

"Regular church attenders [may believe] they have God on their side ... so I don't have that problem of depression or anxiety. That's not my problem. That's somebody else's. ... These same families, that are harder than a rock when it comes to how they feel their faith is and their relationship with God is, but then all of a sudden they are stunned to find a grandchild or son or daughter is struggling with a mental illness and maybe attempted to take their own life."

P7 added, "Health issues or mental health issues were a sign of God's judgment, that we didn't pray enough, that we're sinful".

This view that people of faith won't experience problems of any kind result in a faith community where "we don't talk about our problems. We put on a façade. We look like we've got it all together" (P5). People who struggle with suicide want to "keep up with the Jones" and don't want others to know that "I'm cracking under pressure" (P2).

\subsubsection{Expectation about the "Preaching Moment" (P2)}

Four participants mentioned that preachers and congregants alike expect that religious services will be "nice" (P7) and won't address suicide because "talking about suicide is negative and depressing" (P3). P2 said he feels the pressure of "a strong emphasis on the preaching moment" for congregants to leave church "feeling good." He said, "The preacher, homiletically, feels that the ultimate goal is to make people feel better." He added, "Preaching is a temporary reprieve from the immediate presentation of their pain" because "faith in America has a business aspect to it." Another participant said that congregants want "to hear strictly from the bible and not real life application" (P6). While one preacher said he has brought up suicide in sermons, $\mathrm{C} 1$ empathized that

"Clergy are worried they are going to use the wrong language. They worry if they touch [on suicide], it will get bigger. It will get worse. It will create contagion.

They are concerned about putting the idea in their head."

\subsubsection{Being Busy}

Three participants were clear that faith leaders "are usually stretched pretty thin" (P4). They have "multiple priorities trying to decide where to invest scarce resources of time and energy" (P3). Another added, "there are so many needs out there, and little focus on suicide, so it doesn't get talked about" (P1). P4 added, "Time unfortunately and sometimes money can be a barrier."

\subsubsection{An Artificial Division between Mental Health/Suicide and Faith}

Three participants regretted the separation between mental health/suicide and faith. One said, faith communities "delegate everything to do with the mind to an area out- 
side of theology and ministry ... but life happens in a more integrated way than the compartmentalisations that we have to have in our society" (P2). P4 added,

"In the US we have to separate out faith when it's a public conversation. Most suicide awareness organizations do not address what scripture says about suicide. This creates a gap of conversation about scripture, sin and where is God ... a lack of information means people fill in that blank with old and often negative beliefs, such as suicide is a sin. ... Faith communities are not included in suicide awareness activities in communities. We think we have to separate out faith when it's a public conversation."

Another participant bemoaned that pastors don't see mental health as their business: "One pastor said, 'It's not [pastors'] business to get into your business'" (P6).

\subsubsection{The Lack of Training for Faith Leaders}

One participant pointed to the lack of her training as a faith leader, "When the suicidal gentleman came to me, I felt terribly ill-equipped" (P4). This lack of training may contribute to the artificial division mentioned above.

\subsection{Stigma and Suicide Risk}

Participants were asked if stigma reduces or increases suicide risk. Participants envisioned both possibilities.

\subsubsection{Stigma Decreases Suicide Risk}

P1 said that "Theological distortions can be protective." P2 and P8 agreed that believing a person goes to hell reduces suicide risk. P2 added, "The belief allows people to pause." P7 agreed, "Stigma can make us think twice." C1 gave the example of "the taboo of going to hell had held suicide in check [in the African American church].... Taboos and stigmas can be protective." M1 provided the nuance that while "stigma is going to deter people from doing it, ... I don't think it's necessarily the best deterrent." Many participants agreed with this nuance.

\subsubsection{Stigma Increases Suicide Risk}

Many participants said stigma results in less help-seeking. P1 said, "People think stigma decreases risk of suicide but silence increases risk." P2 explained, "I have to deal with this by myself, to myself. That is a stigma that can hurt." P3 added, "Stigma paralyzes us from taking action." P4 agreed, "Anything that shuts down the conversation or increases isolation increases the likelihood of someone dying of suicide." P7 clarified, "Stigmas can keep people from getting the help they need." $\mathrm{C} 1$ concludes that stigma is more harmful than helpful,

"That taboo is no longer helpful in any church... because you are struggling, you are unworthy and you do not belong to any community, your faith community, your family, your friends, and as a result you are a burden on us and everybody around us. Your existence is a burden."

P8 emphasized that ministry should reach everyone in the church, including people touched by suicide.

\subsection{How to Address Suicide Stigma in Faith Communities}

Participants proposed seven ways to address suicide stigma in faith communities: talk about suicide, address skill deficits, practice vulnerability, get leadership on board, address the theology of suicide, appreciate that faith communities have a unique contribution to make to suicide prevention, and address cultural/systemic issues. 


\subsubsection{Talk about Suicide}

P2 said directly, "Talking about mental health and suicide is how to confront the stigmas." He added that in the 50 plus years he has attended church, "I've never heard a systematic teaching on suicide, ever." P7 said, "Just to name it," especially by weaving in discourse about suicide throughout the year. P1 provided examples of how to do this: "Address stigma publically through prayers, through theology of suffering and mentioning manifestations of suffering [like mental health or suicide]." Several participants said that faith communities have not talked about suicide (C1) but also have not talked about death in general (P5, P8).

$\mathrm{P} 4$ recognizes that talking about suicide requires courage, "It takes people being bold and finding ways to start conversations." M1 suggests that the talk about suicide focus on harm instead of impurity. M1 said, "It's easier for people to have good discourse about something in the domain of harm, when it's framed as a harm-based issue." M1 explains,

"Stigma is more likely to be associated with beliefs about purity [that suicide makes a person morally impure], and because purity does tend to be more indelible and harder to get rid of ... to the extent that stigma is related to ideas about purity and feelings of disgust, we're going to distance ourselves not only from people who attempt or commit suicide but we're going to distance ourselves from the concept, from talking about suicide, by having this purity framework."

M1 explained further "Anything that causes suffering to a conscious being would be considered harmful." He conjectured, "Maybe it's really critical that as soon as the discourse moves away from purity, that it starts to focus on issues of harm." He suggested "moving the idea away from the person and the act toward the community and the consequences to the community; that is a more productive form of discourse".

\subsubsection{Address the Skill Deficits}

One of the skill deficits that needs to be addressed is the ability to talk about difficult topics. P3 said, "If we can help the church talk about suicide, they can talk about just about anything. It's a gateway conversation with a common set of foundational skills and assumptions and values and mission. It opens all those doors." P4 agreed that an important skill is "learning how to talk about subjects that we're not comfortable with." The other skill is being able to listen to one another. P3 said, "There is a basic competency so [congregants] know how to listen to one another." Another skill is help-seeking. P3 said, "Helping people know how to reach out to others, but also how to reach out for help." P4 emphasized that if suicidal congregants reach out for help, then congregants need to be ready to help them because it is likely that a person in need of help will "send a signal to someone around them" (P4). P6 emphasizes that "Knowledge breeds confidence, confidence breeds action." C1 said that while developing skill is important, the larger issue is that clergy may not keep their skills up-to-date. She said,

“There doesn't seem to be a commitment to life-long learning; there doesn't seem to be an understanding that you have to keep yourself current, and you have an obligation to your congregation, to your faith community, to stay current.... we need faith leaders to minister to the needs of suffering people.... you don't have to be an expert. Clergy think they have to be an expert. But they don't, because ministry is all done collaboratively.... [Clergy] are not meeting the needs of their customers.... if they don't get with the times, and educate themselves and stay committed to educating themselves, they are going to stigmatize themselves out of existence."

\subsubsection{Practice Vulnerability}

Participants were clear that the stigma of a suicidal person as "damaged goods" (P1) needs to be addressed. C1 said that one way is to recognize that suicide can touch anyone, that "suicide is a life issue." Other participants said that stigma is addressed through 
vulnerability. P6 emphasized, "One of the things to overcome stigma is vulnerability. Stigma's weapon is vulnerability. You can break stigma with vulnerability." P1 explained how to encourage vulnerability. He said, "We have people tell their stories ... We build community settings where people are encouraged to be utterly frank and transparent with each other over time." P4 explained that it's important for all people of faith to embrace their brokenness. She said,

"Helping to find ways to name that there's brokenness in the world that becomes brokenness in our lives, and the more we can talk about that, the church and God is not a place to bring our shiny, pretty selves but it's there because of our broken selves."

Vulnerability will help to communicate that "[church] is a place where all of you is welcome" (P4). P5 added that this vulnerability will have positive ramifications beyond faith communities. He said,

"You have to be real polished and have it all together. How much different the world would be if we didn't live like that. If we in the church didn't live like that, it would be a real witness to those who are out in the world."

\subsubsection{Address the Theology of Suicide}

Many participants recommended addressing theology. P3 said that a theological understanding of suicide is critical. He asked, "How do we help people understand [suicide] theologically? How do we connect it scripturally?" P4 pointed out that a theological understanding of suicide is critical because there are so few resources: "There are not a lot of resources out there that talk about faith in relation to suicide." P3 gave examples of types of theology to address,

"We need a theology of hope that is more than eschatological ... hope in the here and now, for a life worth living, ... and how to have a life worth living, and how do we support people in finding that life worth living, having that abundant life."

P4 adds that a theology of suffering is important. She said, "God welcomes all questions. God is present. ... God doesn't want people to be in a place where they feel so alone and have no hope for something else." This theology of suffering is important so that suffering people can be ministered to. C1 said, "We have to get our theology straight. That helps people who are suffering, not disenfranchises them or marginalizes them or makes them continue to suffer." She added, "We need to embrace life and we have to be consistent in our [pro-life] mission." P7 emphasized the need to address a theology of healing that says "Don't take your medications; just pray. ... Prayer is enough." She added that theology should address that everyone has problems. M1 emphasized the need to focus on harm instead of purity. He said, "Framing can be really, really powerful".

\subsubsection{Appreciate that Faith Communities Have a Unique Contribution}

Four participants emphasized the unique role of faith communities in suicide prevention. P3 said, "The church is ideally suited to help." P4 added, "[Secular] organizations do not talk about what does scripture actually say about suicide and what do faith communities actually say about suicide ... and when those things aren't talked about, we are missing a huge piece." She added that churches can reflect on the faith questions relating to suicide. "That's one of the pieces that churches should develop and have available." P6 added,

"Churches can assume leadership.... They can take this topic [of suicide] and embrace it.... If we're going to walk away from that, as a Kingdom of God, what are we doing? That's our job.... Where there is trouble, we need to run to it."

P8 emphasized hope. He said, "We are a church that promotes hope in Christ and we reach out to others because of that hope." 


\subsubsection{Get Leadership on Board}

Three participants emphasized the need to get leaders on board with talking about suicide. P1 said, "We need elders and small group leaders to open the conversation about suicide. ... Pastors need to pray publically about desperation and seeking help". C1 suggested that "The Pope should make a statement about suicide.... [because] barriers to address stigma is leadership." P6 said simply, "It comes down to the leadership".

\subsubsection{Address Cultural/Systemic Issues}

Two participants emphasized the need to focus on the faith community's culture and the larger culture. P3 said,

"We have a lot of work to form communities that nurture individuals within them that find that life is really worth living, and when they get to a point of wondering whether it is, know how to have an intersection with that, at that point that is redemptive."

P7 added, "We have to raise the questions of [systemic issues in a community] ... mental health funding has always been the poor step child than physical health funding."

\section{Discussion}

\subsection{Types of Stigma: Internal, Interpersonal and Theological}

Some themes that emerged in the study are consistent with previous studies and some themes that emerged are unique to Christian faith communities and help answer the research question regarding the types of suicide stigma experienced in Christian faith communities. Expected themes include that stigma is experienced internally as a "taint" (Rottman et al. 2014, p. 222) and interpersonally as disconnection from others (McKay and Whitehouse 2015), even a sense of exclusion from groups and denial of access to resources (Binnix et al. 2017).

However, some themes that emerged are unique to Christian faith communities. That a type of stigma found in faith communities is theological makes sense because of Graham and Haidt (2010) characterization of a faith community as a "moral community" (145). Saroglou (2011) clarifies that religion is concerned with morality "from a religious perspective" (p. 1326).

While it was expected that participants might focus on MOS (Lawrence et al. 2016), participants focused on old theological beliefs that reinforce suicide stigma. P4 said that people of faith are likely to misunderstand suicide from their faith perspective because they "fill in that blank with old and often negative beliefs" (P4). P7 explained that "changes in the [Catholic] Catechism take a while to let the average person know that [a Catholic who dies by suicide can be buried in the cemetery]," referring to a change to the Catechism of the Catholic Church promulgated by St. John Paul II in 1992 which added wording that now allows a suicide victim a Catholic funeral and burial (the Catechism of the Catholic Church numbers 2282-2283; Alessi 2014). P8 noted that "there is a strong Catholic influence that seeps into Protestant thinking.")

The silence about suicide occurs because preachers resist talking about suicide explicitly, because of the expectation that congregants leave religious services feeling good and the worry of using "the wrong language" (C1). The result is ignorance about suicide and old theological beliefs about suicide. Another result is an artificial divide between mental health/suicide and faith which prevents faith communities from living into their unique role of integrating faith into discourse about suicide.

These theological beliefs are lived out in a community setting. One of the unexpected themes that surfaced is that people of faith have a theological belief that they must "have it all together" (P5) in their faith community. Not having it all together may result in the individual feeling shame and the faith community shunning a "tainted" (M1) individual. Because of faith communities' skills deficit to have difficult conversations and because of a focus on purity violations, these people are not reaching out for help and faith communities are not ministering to people touched by suicide. 
Internal, interpersonal, and theological stigma seem intertwined, supporting the multidimensional nature of religion as noted by Saroglou (2011), that religion includes dimensions of believing certain doctrines, behaving according to moral principles, and belonging to a community. That suicide stigma is internalized and expressed interpersonally and theologically in a faith community can help conceptualize stigma in faith communities and organize a response to stigma.

\subsection{Stigma and Suicide Risk}

Participants were clear that stigmatizing beliefs (e.g., that suicide is an unforgivable sin) has decreased suicide risk, consistent with Lawrence et al. (2016) who have suggested that religion might reduce suicide risk through shaping a person's beliefs through MOS. But participants were also clear that this stigma deters help-seeking, consistent with Binnix et al. (2017) who found that people with suicide experience hide this experience due to stigma which results in less help-seeking. Participants were clear that stigma is a barrier to expressing emotional vulnerability which inhibits help-seeking (Keller et al. 2019), and that stigma is more likely to increase suicide risk than decrease it.

\subsection{Barriers to Addressing Suicide Stigma}

While suggesting a hopeful path toward addressing stigma in Christian faith communities, participants also discussed barriers to addressing stigma. The first two barriers are silence and ignorance, consistent with Binnix et al. (2017) who found that people who have suicidal experience encounter misunderstanding about suicide because others have inaccurate or no information about suicide because of silence around suicide. Suicide is swept "under the rug" (p. 9), partly because people with suicidal experience fear judgment from others that they are "weak" (Batterham et al. 2013b, p. 19). One respondent in another study said she doesn't disclose suicidality because "there's something about it that might make me feel like it's expressing a vulnerability and a weakness" (Binnix et al. 2017, p. 7). The sense of vulnerability of being seen as weak is similar to what participants described as the expectation of "having it all together" (P5).

That faith leaders don't preach about suicide because of expectations for the "preaching moment" (P2) is a unique barrier to addressing suicide in faith communities. That faith leaders have "time-competing concerns" (p. 13) and a lack of training in suicide (p. 15) are additional barriers consistent with the literature (Marshall 2005) and consistent with a misunderstanding about suicide in society in general (Batterham et al. 2013a).

\subsection{How to Address Suicide Stigma}

Participants described unique ways stigma is experienced but also how Christian faith communities can address these. Participants discussed how each component of stigma has a corresponding way to address it.

Participants said that the internal, interpersonal and theological aspects of stigma can be addressed by talking about suicide directly. Binnix et al. (2017, recommend society gaining more knowledge about suicide by talking about suicide, "Without dialogue, social change is slow and suicidal ideation and attempts will continue to be stigmatized, silenced, and misunderstood" (Binnix et al.). Consistent with the suggestion that increasing suicide literacy and stigma reduction may influence help-seeking (Batterham et al. 2013a), participants suggested that the interpersonal disconnection and shunning can be addressed by assisting the faith community in developing the skills to have difficult conversations to make help-seeking seem less vulnerable and to increase ministry to suffering individuals, consistent with Goffman (1963) who suggests that stigmatized individuals are discredited if their stigma is publicly known, disrupting social interaction particularly when others were ignorant about how to conduct themselves in response to the stigmatized attribute.

Challenging stigma fueled by silence and misunderstanding is in view when participants recommended that people with lived experience of suicide share vulnerably about their experiences (e.g., Jamison 1995; National Action Alliance for Suicide Prevention: 
Suicide Attempt Survivors Task Force 2014). Jamison (1995) has written: "I am tired of hiding, tired of misspent and knotted energies, tired of the hypocrisy, and tired of acting as though I have something to hide" (p. 7). Participants suggested that by modeling vulnerability, members of faith communities can show that suicidal behaviors do not indicate a weak faith.

Participants suggested that faith communities challenge old theological beliefs directly through discourse about suicide in religious services throughout the year. Participants' suggestion is consistent with one of the first competencies faith leaders need in order "to support faith, hope, and life before, during, and after a suicidal crisis in an informed, caring, and effective way" (National Action Alliance for Suicide Prevention: Faith Communities Task Force 2019, p. 5) which is preaching and teaching about suicide.

Consistent with getting leaders on board, leadership involvement in change is assumed in organizational approaches to culture shift (Katzenbach et al. 2012). Consistent with living into the unique role of faith communities of integrating faith perspectives with suicide, Goal 1 of the 2012 National Strategy for Suicide Prevention (HHS 2012) emphasizes the importance of infusing suicide prevention into a broad range of organizations including faith-based programs in order to "promote greater understanding of suicide and help counter the prejudice, silence, and denial that can prevent individuals from seeking help" (p. 30).

The skill deficits of faith leaders in addressing suicide is a well-documented theme in the literature (Marshall 2005). In a sample of 801 Catholic, Jewish and Protestant clergy, $32 \%$ of respondents reported no formal suicide training (Mason et al. 2016); about a third reported being very uncertain or uncertain in their work with suicidal people and $86 \%$ endorsed the need for more suicide-related training (Mason et al. 2021). A respondent in the study explained,

"The counseling courses I took for my MDiv were entirely, without doubt, lacking any substance, actual training, or real merit. We were told to refer. That's all. And while I agree that I am not trained to serve as someone's therapist or psychiatrist, I am, all too often, the first person they come to when fighting depression or suicide." (Mason et al. 2021, p. 87)

Suicide-specific training is important because it has been found to be associated with interventions more concurrent with suicide prevention experts (Mason et al. 2016) and use of more suicide-prevention competencies (Mason et al. 2020a).

Participants suggested that faith communities address cultural differences and systemic issues by being sensitive to their context, consistent with McKay and Whitehouse (2015) who write, "the religious constellation may look quite different from one cultural perspective than it does from another" (p. 450). As noted by the Surgeon General, "culture counts" (HHS 2001, p. 25). For example, cultural beliefs about mental illness are related to a country's suicide rates (Schomerus et al. 2015). An example of addressing systemic issues might be addressing the higher prevalence of suicidal behaviors among sexual minority youth (Marshal et al. 2011) perhaps related to stigmatizing religious beliefs (Yarhouse et al. 2018).

A last participant suggestion is that the faith community focus on the harm to suicidal individuals instead of on purity violations which taint. A focus on harm instead of purity violations would mean that faith communities need to see the harm that suicide does to the community but also the harm that the faith community is doing to the person touched by suicide. While suicide leaves behind a devastated community, shunning and not reaching out to a person touched by suicide harms that individual, who deserves their fair share of the ministry of the faith community. Koleva et al. (2012) have highlighted five core foundations in MFT: care-harm, fairness-cheating, in-group loyalty-betrayal, respect for authority-subversion, and purity-degradation. Using MFT, we can apply the findings of the study to focus on care to the person touched by suicide while at the same time pointing out that the person touched by suicide is not getting their fair share of ministry, they are undeservedly being betrayed into an out-group, and following God's authority we should 
love them, despite any moral violation. With this focus, faith communities can do what one study participant called "actively remove the stigma" (Mason et al. 2020b).

\section{Limitations and Future Directions}

As noted by Kral et al. (2012), suicide research has been primarily quantitative. A strength of this study is the qualitative approach, but findings are applicable only to the nine U.S. Christian participants, the U.S. faith communities represented in the sample, and one moral psychologist based in the U.S. The findings need to be tested on larger and more diverse samples. The limitations of this research should be addressed in future investigations.

\section{Conclusions}

Faith communities have a unique role in suicide prevention, integrating faith into the suicide prevention discourse. Several barriers prevent them from living into this role including silence around suicide resulting in stigma based on old theological beliefs and an artificial divide between faith and suicide prevention. One of the old theological belief is that Christians must "have it all together" (P5) in their faith community. Due to this belief, Christian faith communities are not ministering to people touched by suicide and these people are not reaching out for help. Several recommendations for addressing suicide stigma include integrating talk about suicide in religious services, sharing vulnerably about one's suicidal behaviors, focusing on suicide as a harm violation instead of a purity violation, which will create a community where suicidal individuals can reach out for help and the faith community can minister to people touched by suicide.

Funding: This research received no external funding.

Institutional Review Board Statement: Gordon-Conwell Theological Seminary's Institutional Review Board approved the study on 25 January 2021. The study was conducted according to the guidelines of the Declaration of Helsinki, and as approved by the Gordon-Conwell Theological Seminary Institutional Review Board.

Informed Consent Statement: Informed consent was obtained from all subjects involved in the study.

Data Availability Statement: Data can be obtained from the author.

Conflicts of Interest: The author declares no conflict of interest.

\section{Appendix A}

A sample of interview questions:

1. How do you define stigma?

2. What stigmas about suicide (e.g., suicidal thinking, suicide attempts, suicide death, copycat suicide) exist in faith communities?

3. Do some stigmas like believing that those who die by suicide go to hell reduce risk of suicide?

4. Do some stigmas increase risk of suicide?

5. How has stigma about suicide been addressed in a faith community?

6. How do faith communities address the barrier of addressing suicide stigma?

\section{References}

Alessi, Scott. 2014. Is Suicide a sin? Catholic Teaching on Suicide Hasn't Changed, but it has Become More Nuanced. U.S. Catholic. October 28. Available online: https:/ / uscatholic.org/articles/201410/is-suicide-a-sin/ (accessed on 28 June 2021).

Allen-Ervin, Alice. 2017. Exploring the Role of Shame and Stigma Surrounding Suicidal Depression Among Christians. Ph.D. dissertation, California Southern University, Costa Mesa, CA, USA. Proquest number 10747276.

Batterham, Philip J., Alison L. Calear, and Helen Christensen. 2013a. Correlates of suicide stigma and suicide literacy in the community. Suicide and Life-Threatening Behavior 43: 406-17. [CrossRef] 
Batterham, Philip J., Alison L. Calear, and Helen Christensen. 2013b. The Stigma of Suicide Scale. Psychometric properties and correlates of the stigma of suicide. Crisis 34: 13-21. [CrossRef]

Binnix, Taylor M., Carol Rambo, Seth Abrutyn, and Anna S. Mueller. 2017. The dialectics of stigma, silence, and misunderstanding in suicidality survival narratives. Deviant Behavior 29: 1095-106. [CrossRef]

Braun, Virginia, and Victoria Clarke. 2006. Using thematic analysis in psychology. Qualitative Research in Psychology 3: 77-101. [CrossRef]

Braun, Virginia, and Victoria Clarke. 2012. Thematic analysis. In APA Handbook of Research Methods in Psychology: Vol. 2. Research Designs: Quantitative, Qualitative, Neuropsychological and Biological. Edited by Harris Cooper, Paul Camic, Debra Long, Abigail T. Panter, David Rindskopf and Kenneth Sehr. Washington, DC: American Psychological Association, pp. 57-71.

Braun, Virginia, and Victoria Clarke. 2013. Successful Qualitative Research: A Practical Guide for Beginners. Los Angeles: Sage.

Centers for Disease Control and Prevention, National Center for Injury Prevention and Control [CDC]. 2005. Web-Based Injury Statistics Query and Reporting System (WISQARS). Available online: www.cdc.gov/injury/wisqars (accessed on 13 May 2021).

Chakroff, Alek, and Liane Young. 2015. Harmful situations, impure people: An attribution asymmetry across moral domains. Cognition 136: 30-37. [CrossRef]

Chida, Yoichi, Andrew Steptoe, and Lynda H. Powell. 2009. Religiosity/Spirituality and Mortality. Psychotherapy and Psychosomatics 78: 81-90. [CrossRef] [PubMed]

Creswell, John W. 2014. Research Design: Qualitative, Quantitative and Mixed Method Approaches, 4th ed. Thousand Oaks: Sage.

Eskin, Mehmet. 2004. The effects of religious versus secular education on suicide ideation and suicidal attitudes in adolescents in Turkey. Social Psychiatry and Psychiatric Epidemiology 39: 536-42. [CrossRef] [PubMed]

Gergen, Kenneth J., Ruthellen Josselson, and Mark Freeman. 2015. The promises of qualitative inquiry. American Psychologist 70: 1-9. [CrossRef]

Goffman, Erving. 1963. Stigma: Notes on the Management of Spoiled Identity. New York: Simon \& Schuster.

Goodwill, Janelle R., and Sasha Zhu. 2020. Association between perceived public stigma and suicidal behaviors among college students of color in the U.S. Journal of Affective Disorders 1: 1-7. [CrossRef]

Graham, Jesse, and Jonathan Haidt. 2010. Beyond beliefs: Religions bind individuals into moral communities. Personality and Social Psychology Review 13: 140-50. [CrossRef] [PubMed]

Graham, Jesse, Brian A. Nosek, Jonathan Haidt, Ravi Iyer, Sena Koleva, and Pete H. Ditto. 2011. Mapping the moral domain. Journal of Personality and Social Psychology 101: 366-85. [CrossRef]

Haidt, Jonathan, and Craig Joseph. 2004. Intuitive ethics: How innately prepared intuitions generate culturally variable virtues. Daedalus 133: 55-66. [CrossRef]

Hedegaard, Holly, Arialdi M. Miniño, and Margaret Warner. 2020. Drug Overdose Deaths in the United States, 1999-2018. NCHS Data Brief, no. 356. Hyattsville: National Center for Health Statistics.

Holt-Lunstad, Julianne. 2017. The potential public health relevance of isolation and loneliness: Prevalence, epidemiology, and risk factors. Public Policy \& Aging Report 27: 127-30.

Jamison, Kay Redfield. 1995. An Unquiet Mind: A Memoir of Moods and Madness. New York: Vintage Books.

Katzenbach, Jon R., Ilona Steffen, and Caroline Kronley. 2012. Cultural change that sticks. Harvard Business Review 90: 110-17.

Keller, Sarah, Vanessa McNeill, Joy Honea, and Lani Paulson Miller. 2019. A look at culture and stigma of suicide: A textual analysis of community theatre performances. International Journal of Environmental Research and Public Health 16: 352. [CrossRef]

Koleva, Sena P., Jesse Graham, Ravi Iyer, Pete H. Ditto, and Jonathan Haidt. 2012. Tracing the threads: How five moral concerns (especially Purity) help explain culture war attitudes. Journal of Research in Personality 46: 184-94. [CrossRef]

Kral, Michael J., Paul S. Links, and Yvonne Bergmans. 2012. Suicide Studies and the Need for Mixed Methods Research. Journal of Mixed Methods Research 6: 236-49. [CrossRef]

Lawrence, Ryan E., Maria A. Oquendo, and Barbara Stanley. 2016. Religion and suicide risk: A systematic review. Archives of Suicide Research 20: 1-21. [CrossRef]

Li, Shanshan, Meir J. Stampfer, David R. Williams, and Tyler J. VanderWeele. 2016a. Association of religious service attendance with mortality among women. JAMA Internal Medicine 176: 777-85. [CrossRef] [PubMed]

Li, Shanshan, Olivia I. Okereke, Shun-Chiao Chang, Ichiro Kawachi, and Tyler J. VanderWeele. 2016b. Religious service attendance and lower depression among women-A prospective cohort study. Annals of Behavioral Medicine 50: 876-84. [CrossRef] [PubMed]

Marshal, Michael P., Laura J. Dietz, Mark S. Friedman, Ron Stall, Helen Smith, James McGinley, Brian C. Thoma, Pamela J. Murray, Anthony D'Augelli, and David A. Brent. 2011. Suicidality and depression disparities between sexual minority and hetersexual youth: A meta-analytic review. Journal of Adolescent Health 49: 115-23. [CrossRef]

Marshall, Doreen S. 2005. Clergy Workgroup on Suicide Prevention and Aftercare. Retrieved from Suicide Prevention Resource Center Website. Available online: http:/ / www.sprc.org/sites/sprc.org/files/library/faithbasedconf.pdf (accessed on 13 May 2021).

Mason, Karen, Esther Kim, and W. Blake Martin. 2020a. Clergy use of suicide prevention competencies. OMEGA-Journal of Death and Dying 8: 404-23. [CrossRef]

Mason, Karen, Frank Robinson, Zihan Yang, Karen Colaneri, Luke Buescher, Ju-In Lee, and Amy Smith. 2020b. How counselors can help faith communities lower suicide risk: A qualitative study. Manuscript submitted for publication (under review).

Mason, Karen, Monica Geist, and Mollie Clark. 2019a. A developmental model of clergy engagement with suicide: A qualitative study. OMEGA-Journal of Death and Dying 79: 347-63. [CrossRef] 
Mason, Karen, Monica Geist, Richard Kuo, Day Marshall, and James D. Wines Jr. 2016. Predictors of clergy's ability to fulfill a suicide prevention gatekeeper role. Journal of Pastoral Care and Counseling 70: 34-39. [CrossRef]

Mason, Karen, Monica Geist, Richard Kuo, Day Marshall, and James D. Wines Jr. 2021. Clergy as suicide prevention gatekeepers. Journal of Pastoral Care \& Counseling 75: 84-101.

Mason, Karen, Yuan Hu, Esther Kim, David Korver, Lisa Xia, and Nick Coniglio. 2019b. Unique experiences in religious groups, in the U.S. and China-A qualitative study. Journal of Mental Health, Religion and Culture 21: 609-24. [CrossRef]

McKay, Ryan, and Harvey Whitehouse. 2015. Religion and morality. Psychological Bulletin 141: 447-73. [CrossRef] [PubMed]

National Action Alliance for Suicide Prevention: Faith Communities Task Force. 2019. Suicide Prevention Competencies for Faith Leaders: Supporting Life before, during, and after a Suicidal Crisis. Washington, DC: Education Development Center, Inc.

National Action Alliance for Suicide Prevention: Suicide Attempt Survivors Task Force. 2014. The Way Forward: Pathways to Hope, Recovery, and Wellness with Insights from Lived Experience. Washington, DC: Author.

Rottman, Joshua, and Liane Young. 2019. Specks of dirt and tons of pain: Dosage distinguishes impurity from harm. Psychological Science 30: 1151-60. [CrossRef]

Rottman, Joshua, Deborah Kelemen, and Liane Young. 2014. Tainting the soul: Purity concerns predict moral judgments of suicide. Cognition 130: 217-26. [CrossRef] [PubMed]

Saroglou, Vassilis. 2011. Believing, Bonding, Behaving, and Belonging: The Big Four Religious Dimensions and Cultural Variation. Journal of Cross-Cultural Psychology 42: 1320-40. [CrossRef]

Schomerus, Georg, Sara Evans-Lacko, N. Rusch, Ramin Mojtabai, Matthias C. Angermeyer, and Graham Thornicroft. 2015. Collective levels of stigma and national suicide rates in 25 European countries. Epidemiology and Psychiatric Sciences 24: 166-71. [CrossRef]

Tannenwald, Nina. 2007. The Nuclear Taboo: The United States and the Non-Use of Nuclear Weapons Since 1945. Cambridge: Cambridge University Press.

Tetlock, Philip E. 2003. Thinking the unthinkable: Sacred values and taboo cognitions. TRENDS in Cognitive Sciences 7: 320-24. [CrossRef]

Tybur, Joshua M., Debra Lieberman, Robert Kurzban, and Peter DeScioli. 2013. Disgust: Evolved function and structure. Psychological Review 120: 65-84. [CrossRef]

U.S. Department of Health and Human Services [HHS]. 2001. Mental Health: Culture, Race, and Ethnicity-A Supplement to Mental Health: A Report of the Surgeon General; Rockville: U.S. Department of Health and Human Services, Substance Abuse and Mental Health Services Administration, Center for Mental Health Services.

U.S. Department of Health and Human Services [HHS]. 2012. Office of the Surgeon General and National Action Alliance for Suicide Prevention. 2012 National Strategy for Suicide Prevention: Goals and Objectives for Action; Washington, DC: HHS.

VanderWeele, Tyler J. 2018. Religious Communities, Health, and Well-Being-Address to the US Air Force Chaplain. Military Medicine 183: 105-9. [CrossRef] [PubMed]

VanderWeele, Tyler J., Julie R. Palmer, and Alexandra E. Shields. 2017. VanderWeele et al. Respond to 'Church Attendance and Mortality'. American Journal of Epidemiology 185: 526-28. [CrossRef]

VanderWeele, Tyler J., Shanshan Li, Alexander C. Tsai, and Ichiro Kawachi. 2016. Association between religious service attendance and lower suicide rates among US women. JAMA Psychiatry 73: 845-51. [CrossRef]

Yarhouse, Mark A., Janet B. Dean, Stephen P. Stratton, and Michael Lastoria. 2018. Listening to Sexual Minorities: A Study of Faith and Sexual Identity on Christian College Campuses. Downers Grove: IVP Academic. 